\title{
Synthesis and Spectral Characterization of Novel Spiroindan-1,3-Dione: A Diels Alder Adduct
}

\author{
N. D. Zargar and K. Z. Khan \\ Department of Chemistry, University of Kashmir, Srinagar, 190006 Jammu and Kashmir, India \\ Correspondence should be addressed to N. D. Zargar; nded.1092@rediffmail.com
}

Received 25 August 2013; Revised 24 November 2013; Accepted 8 December 2013

Academic Editor: Luqman Chuah Abdullah

Copyright (c) 2013 N. D. Zargar and K. Z. Khan. This is an open access article distributed under the Creative Commons Attribution License, which permits unrestricted use, distribution, and reproduction in any medium, provided the original work is properly cited.

$\mathrm{DMSO} / \mathrm{Ac}_{2} \mathrm{O}$ reagent converts 1,3-indandione (1) to an unusual dimer $1 \mathrm{H}, 1^{\prime} \mathrm{H}-2,2^{\prime}$-biindene-1,1 $1^{\prime}, 3,3^{\prime}\left(2 \mathrm{H}, 2^{\prime} \mathrm{H}\right)$ tetrone and a dimeric condensation product along with an ylide (1a) at room temperature. This reagent also brings about oxidation of secondary alcohols to corresponding ketones, methyl thiomethylation, and N-hydroxymethylation in phthalimide and converts 4-hydroxycoumarins and dicoumarol to different oxidative and degradation products under varying conditions. However, when 1,3-indandione was refluxed with $\mathrm{DMSO} / \mathrm{Ac}_{2} \mathrm{O}$ reagent at $150^{\circ} \mathrm{C}$, it afforded a novel compound, 2-spiroindan 1,3-dione (2), a Diels Alder Adduct, analogous to (3) obtained upon treatment of 1,3-indandione with formaldehyde in presence of primary amines.

\section{Introduction}

Dimethyl sulphoxide, a polar aprotic liquid, has been used in combination with a number of activators but the most important and extensively used was acetic anhydride. DMSO-acetic anhydride reagent has been a subject of monographs. It brings about oxidative rearrangements [1], oxidative degradation, oxidation of secondary alcohols [2], and methyl thiomethylates $-\mathrm{OH}$ group in different sugar units [3]. Interaction of this reagent with 4-hydroxy coumarins and 3-substituted 4hydroxy coumarins results in a wide range of products under varying conditions both of mechanistic and pharmacological interests [4].

1,3-Indandione, a member of class of I,3-diketo compounds has been found to yield a number of compounds with different substrates having marked chemical and biological activities. Its interaction with 5-bromo furfural in ethanol gives 5-bromo furfuryl diindandionyl-methane [5]. It reacts with cyclic ketones such as cyclopentanone and cyclohexanone to give the corresponding 2-cycloalkylidene1,3-indandione [6]. 1,3-Indandione also reacts with indazoladione and furnishes a condensation product [7].

3-Substituted-1,3-indandione shows Michael addition reaction with $\beta$-nitro vinyl benzene to give an adduct having fungicidal property which depends upon the type and location of the substituent on aryl residue [8]. In a double Michael addition reaction 1,3-indandione has been found to interact with 1,5-diphenyl-pentadiene-3-one in a (-) quinone catalyzed stereo-specific reaction to give optically active trans-spiran [9]. 1,3-Indandione also undergoes condensation reaction with aromatic aldehydes to give 2arylidine-1,3-indandione [10]. Reaction of 1,3-indandione with active methylene compounds such as malononitrile has been found to give a number of compounds [11]. Its condensation with heteroatom carbaldehydes has been found to give 2-alkylidenes which undergo Michael addition of 1,3-indandione to yield a $2: 1$ adduct [12]. Inter- and intramolecular $\mathrm{C}-\mathrm{H} \cdots \mathrm{O}$ bonding have also been observed in the anions of 1,3-indandione derivatives [13].

Keeping in view it was thought better to interact 1,3indandione with DMSO-acetic anhydride reagent at elevated temperature $\left(\sim 150^{\circ} \mathrm{C}\right)$ as the former contains active hydrogens which can protonate the oxygen of DMSO and set the reaction in motion.

\section{Experimental}

2.1. General Comments. Solvents purchased from Merck were of AR grade. 1,3-Indandione was received from Guide Chem. DMSO was carefully dried according to the standard 


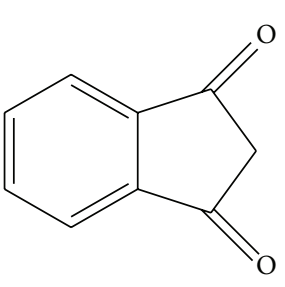

(1)

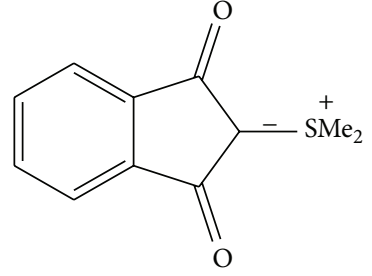

(1a)
Figure 1: Substrate I, 3-indandione. (1a) Ylide.<smiles>O=C1C2=C(OCC3(C2)C(=O)c2ccccc2C3=O)c2ccccc21</smiles>

(2)

Figure 2: Novel compound 2-spiroindan 1,3-dione.

procedure [14]. All reactions were monitored by TLC plates precoated with Silica gel $\mathrm{Si}_{60} \mathrm{~F}_{254}$ from Merck. Melting points were recorded on Tempo block melting point apparatus and are uncorrected. IR spectra were recorded on Perkin Elmer spectrophotometer of the range $4000-400 \mathrm{~cm}^{-1}$. ${ }^{1} \mathrm{HNMR}$ was recorded on $300 \mathrm{MHz}$ Bruker instrument. Mass was recorded on Jeol mass spectrometer in electron ionization mode. Ylide (1a) was synthesized by the earlier reported method [15].

2.2. 2-Spiroindan-1,3-Dione. A mixture of 1,3-indandione $(1 \mathrm{~g})$, DMSO $(16 \mathrm{~mL})$, and acetic anhydride $(8 \mathrm{~mL})$ was maintained at $\sim 150^{\circ} \mathrm{C}$ in an oil bath for eight hours. TLC monitoring indicated formation of a mixture of products. The reaction mixture was cooled, diluted with excess of water, and extracted with ether. The ether layer was washed several times with water and dried over anhydrous sodium sulphate and removal of solvent afforded a gummy residue, column chromatography of which over silica gel gave only one pure product in good yields m.p. $244-246^{\circ} \mathrm{C}$. The compound was found to be devoid of sulphur:

Ylide (1a), yield (52.5\%), m.p. $165^{\circ} \mathrm{C}^{1} \mathrm{HNMR} \mathrm{CDCl} 3$, $300 \mathrm{MHz},(\delta), \mathrm{ppm})$,

$$
\begin{aligned}
& 3.024\left(6 \mathrm{H}, \mathrm{s}, \mathrm{S}^{+}\left(\mathrm{CH}_{3}\right)_{2}, 7.760-7.946(4 \mathrm{H} . \mathrm{m}, \mathrm{Ar}-\mathrm{H})\right. \\
& \left.v_{\max }(\mathrm{KBr}) \mathrm{cm}^{-1}\right) 1635 \text { and } 1595 \mathrm{~cm}^{-1}, \\
& \text { 2-Spiroindan 1,3-dione (2) yield (59\%), M.P. 244- } \\
& \text { 246 }{ }^{\circ} \mathrm{C},{ }^{1} \mathrm{HNMR} \text { DMSO-d } \\
& 6
\end{aligned}
$$

$2.48\left(2 \mathrm{H}, \mathrm{s},=\mathrm{C}-\mathrm{CH}_{2}-\mathrm{C}-\right), 3.34\left(2 \mathrm{H}, \mathrm{s}, \mathrm{O}-\mathrm{CH}_{2}-\mathrm{C}-\right)$ 7.02-7.97 (8H, m, Ar-H),

$v_{\max }(\mathrm{KBr}) \mathrm{cm}^{-1} 1710$ (shoulder) 1700, 1570, 1400, 1340 , and $1230 \mathrm{~cm}^{-1}$,

Mass $\mathrm{M}^{+}(m / z) 316,288,158$, and 76.

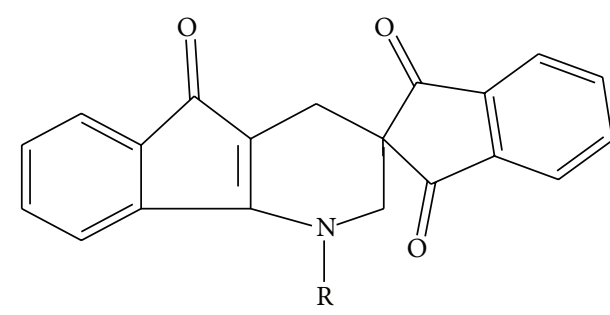

(3)

$\mathrm{R}=$ Allyl, Aryl

Figure 3: Analogous Spiro compound of (2).

\section{Results and Discussion}

The reaction between 1,3-indandione and $\mathrm{DMSO} / \mathrm{Ac}_{2} \mathrm{O}$ reagent at room temperature has been found to afford an unusual dimer $1 \mathrm{H}, 1^{\prime} \mathrm{H}-2,2^{\prime}$-biindene- $1,1^{\prime}, 3,3^{\prime}\left(2 \mathrm{H}, 2^{\prime} \mathrm{H}\right)$ tetrone, a dimeric condensation product along with an ylide (1a) in better yields than those reported earlier [15]. However, when 1,3-indandione was refluxed with this versatile reagent at $150^{\circ} \mathrm{C}\left( \pm 5^{\circ} \mathrm{C}\right)$, the reaction proved to be destructive; that is, instead of two enantiomers TLC monitoring indicated the formation of a number of products which could not be resolved. Workup of the reaction mixture and chromatography of the material resulted in only one pure compound m.p. $244-246^{\circ} \mathrm{C}$ and was found to be devoid of sulphur. On the basis of elemental analysis and mass spectrum showing $\mathrm{M}^{+}$ at $m / z 316$, its molecular formula was found to be $\mathrm{C}_{20} \mathrm{H}_{12} \mathrm{O}_{4}$ and the structure ultimately assigned to this compound is (2) (Figures 1 and 2).

The ${ }^{1}$ HNMR spectrum of this compound was extremely simple showing two singlets equivalent to two protons each at $\delta 2.48$ and 3.34 and a multiplet equivalent to eight protons in the aromatic region at $\delta 7.20-7.97$. This suggests involvement of two indandione molecules and two methylene groups most certainly derived from DMSO in the formation of this compound. The structure (2) assigned to this compound is also supported by its IR spectrum showing strong carbonyl bands at 1700 and $1710 \mathrm{~cm}^{-1}$. It is analogous to the compound (3) obtained upon treatment of 1,3-indandione with formaldehyde in presence of primary amines [16] (Figure 3).

Formation of this compound at elevated temperature $\left(150^{\circ} \mathrm{C}\right)$ is understandable on the basis that 2-hydroxymethyl or 2-methylthiomethyl-1,3-indandione initially formed in this reaction can decompose at this temperature to yield (4) dimerisation of which through Diels Alder reaction gives the Spiro product (2) (Scheme 1).

\section{Conclusion}

Synthesis of this novel compound was confirmed by different spectral techniques. Its IR and ${ }^{1}$ HNMR studies suggest the oxidative cyclizations involving methylene group of one indandione moiety and the carbonyl group of the other. Silica gel used for chromatographic techniques worked as 


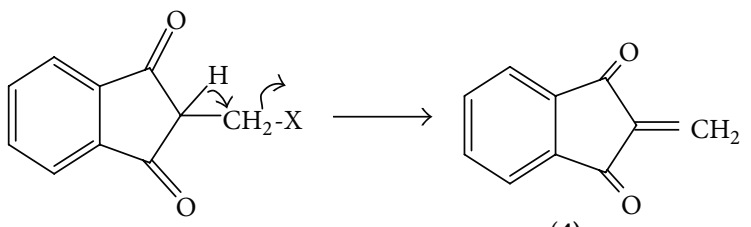

(4)

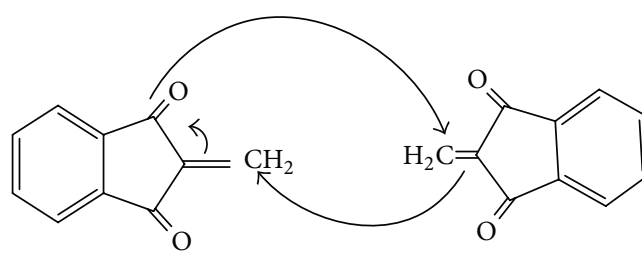<smiles>O=C1C2=C(OCC3(C2)C(=O)c2ccccc2C3=O)c2ccccc21</smiles>

$\mathrm{X}=\mathrm{OH}$ or $-\mathrm{SMe}$

SCHEMe 1

a good adsorbent and showed better resolution than other adsorbents.

\section{Acknowledgments}

The authors are highly thankful to RSIC Punjab University Chandigarh, India, for recording ${ }^{1} \mathrm{HNMR}$, IR, mass spectra, and elemental analysis. N. D. Zargar is also thankful to the Department of Chemistry, University of Kashmir, for providing all the research facilities.

\section{References}

[1] R. J. Wikholm and H. W. Moore, "Dimethyl sulfoxideacetic anhydride oxidative rearrangements of hydroxyterphenylquinones. A possible biosynthetic model," Journal of the American Chemical Society, vol. 94, no. 17, pp. 6152-6158, 1972.

[2] M. S. Newman and R. L. Childers, "Attempted preparation of new phenanthrenequinone types," Journal of Organic Chemistry, vol. 32, no. 1, pp. 62-66, 1967.

[3] R. Toman, V. Kavaciteand, and M. Kubackova, Chemical Abstracts, 93, 150578d, 1980.

[4] K.-Z. Khan, N. Minhaj, K. Tasneen et al., "The reaction of dimethyl sulphoxide and acetic anhydride with 4hydroxycoumarin and dicoumarol," Journal of the Chemical Society, Perkin Transactions I, pp. 841-849, 1983.

[5] L. Geita and G. Vanags, Chemical Abstracts, 59, 7458, 1963.

[6] F. J. Kunz and O. E. Polansky, "Reaction of some ketones and ketimines with indandion-(1,3)," Monatshefte für Chemie, vol. 100, no. 1, pp. 95-105, 1969.

[7] Y. A. Strakov, B. Y. Slude, M. V. Petrova, and V. Mishnew, Chemical Abstracts, 125, 142660p, 1996.

[8] J. Kaminski, A. Skupni, and M. Stec, Chemical Abstracts, 87, 117698w, 1997.

[9] W. Ten Hoeve and H. Wynberg, "Chiral spiranes. Optical activity and nuclear magnetic resonance spectroscopy as a proof for stable twist conformations," Journal of Organic Chemistry, vol. 44, no. 9, pp. 1508-1514, 1979.

[10] I. Zilniece and A. Zicminas, Chemical Abstracts, 102, 95604, 1985.

[11] T. Uyar, Chemical Abstracts, 119, 95051e, 1993.
[12] C. Franz, G. Heinisch, W. Holzer, K. Mereiter, B. Strobl, and C. Zheng, "Reaction products of 1, 3-indandione with heteroaromatic carbaldehydes: synthesis, structure and NMR investigations," Heterocycles, vol. 41, no. 11, pp. 2527-2551, 1995.

[13] M. Sigalov, P. Krief, L. Shapiro, and V. Khodorkovsky, "Interand intramolecular $\mathrm{C}-\mathrm{H} \cdots \mathrm{O}$ bonding in the anions of 1,3indandione derivatives," European Journal of Organic Chemistry, no. 4, pp. 673-683, 2008.

[14] A. I. Vogel, A. R. Tatchell, B. S. Furnis, A. J. Hannaford, and P. W. G. Smith, Vogel's Text Book of Practical Organic Chemistry, 1994.

[15] N. D. Zargar and K. Z. Khan, "Synthesis and characterization of 2-substituted derivatives of 1, 3-indandione," Global Journal of Science Frontier Research, vol. 12, no. 5, pp. 45-48, 2012.

[16] H. Moehrle and S. Doernbrack, Chemical Abstracts, 96, 104045, 1982. 

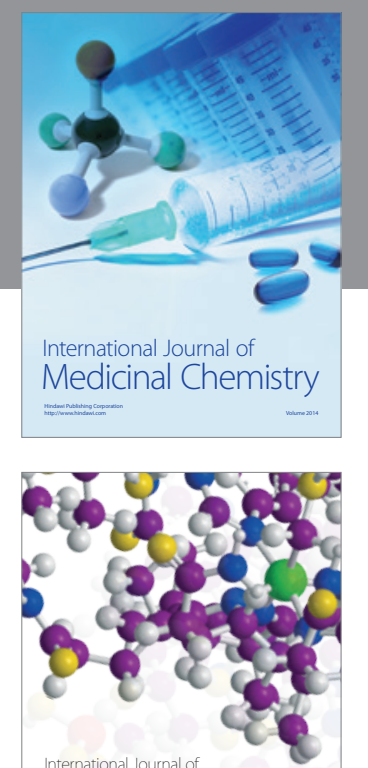

\section{Carbohydrate} Chemistry

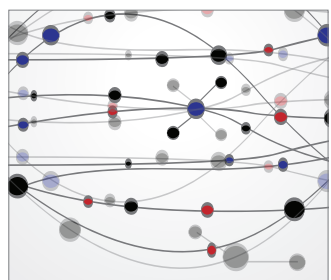

The Scientific World Journal
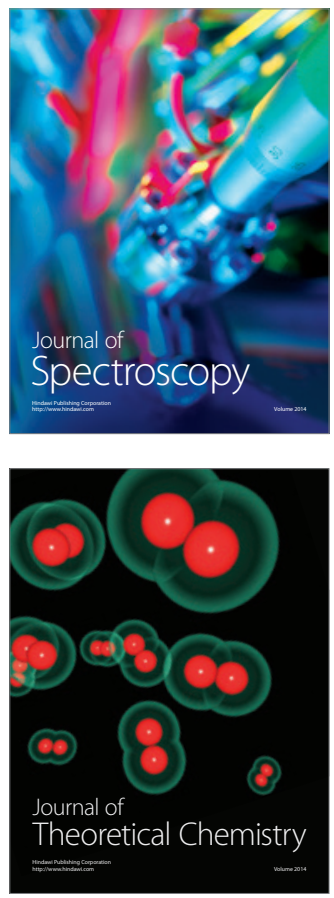
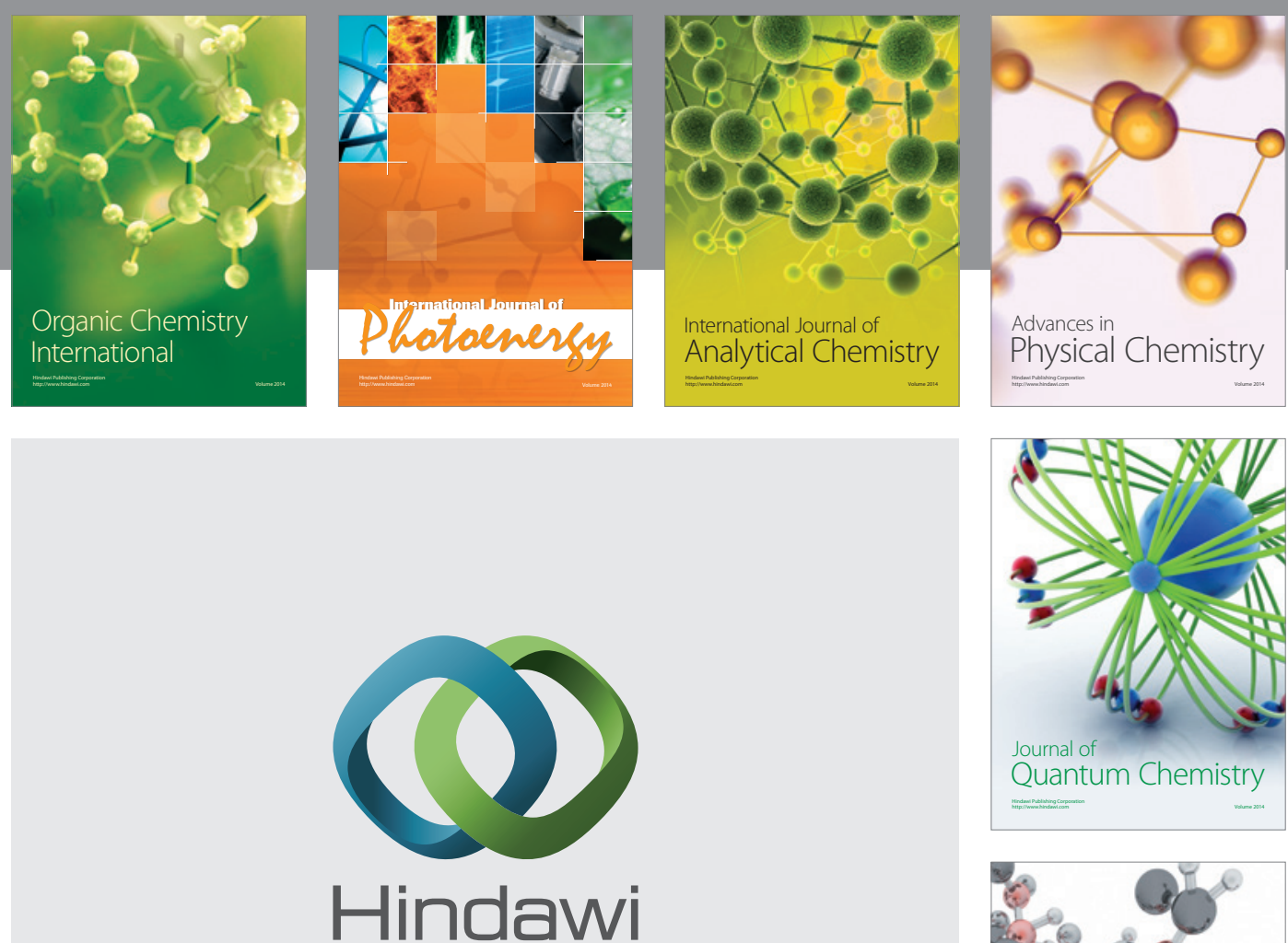

Submit your manuscripts at

http://www.hindawi.com

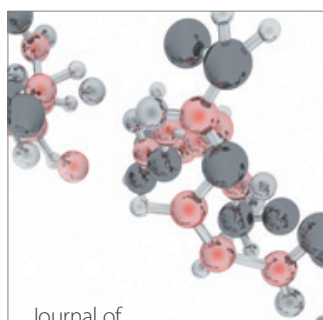

Analytical Methods

in Chemistry

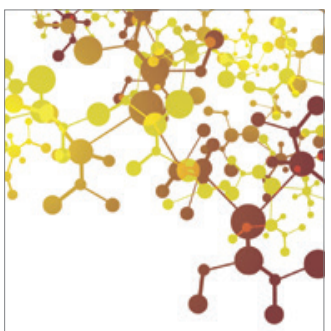

Journal of

Applied Chemistry

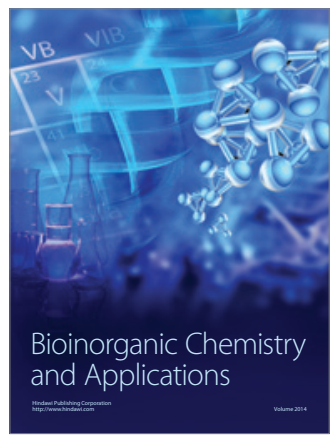

Inorganic Chemistry
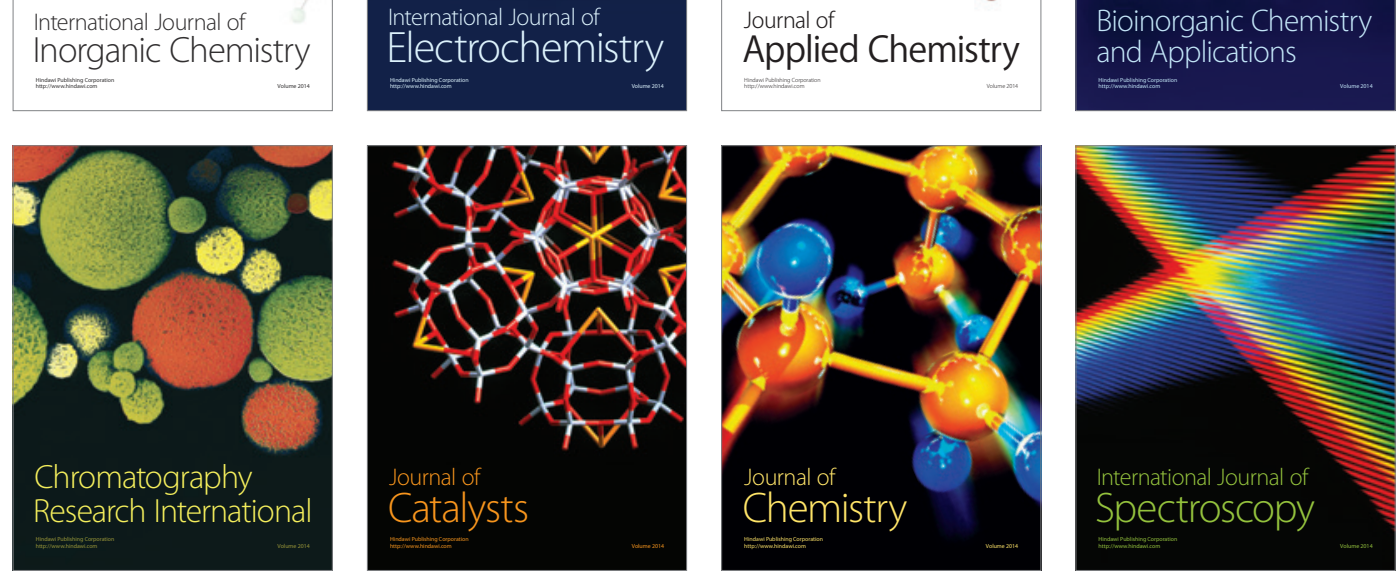